\title{
Surface treated fly ash filled modified epoxy composites
}

\author{
Uma Dharmalingam¹, Meenakshi Dhanasekaran', Kothandaraman Balasubramanian \\ and Ravichandran Kandasamy*
}

\author{
${ }^{1}$ Polymer Chemistry Laboratory, Department of Rubber and Plastics Technology, \\ Madras Institute of Technology Campus, Anna University, Chennai, Tamil Nadu, India \\ *ravi@mitindia.edu
}

\begin{abstract}
Fly ash, an inorganic alumino silicate has been used as filler in epoxy matrix, but it reduces the mechanical properties due to its poor dispersion and interfacial bonding with the epoxy matrix. To improve its interfacial bonding with epoxy matrix, surface treatment of fly ash was done using surfactant sodium lauryl sulfate and silane coupling agent glycidoxy propyl trimethoxy silane. An attempt is also made to reduce the particle size of fly ash using high pressure pulverizer. To improve fly ash dispersion in epoxy matrix, the epoxy was modified by mixing with amine containing liquid silicone rubber (ACS). The effect of surface treated fly ash with varying filler loadings from 10 to $40 \%$ weight on the mechanical, morphological and thermal properties of modified epoxy composites was investigated. The surface treated fly ash was characterized by particle size analyzer and FTIR spectra. Morphological studies of surface treated fly ash filled modified epoxy composites indicate good dispersion of fillers in the modified epoxy matrix and improves its mechanical properties. Impact strength of the surface treated fly ash filled modified epoxy composites show more improvement than unmodified composites.
\end{abstract}

Keywords: fly ash, poly dimethyl siloxane-co-amino propyl methyl siloxane, silane coupling agent, surfactant.

\section{Introduction}

Organic-inorganic hybrid composites have gained immense attention from the researchers, as they combine the advantages of both inorganic solids such as high mechanical, thermal and structural stability and the characteristics of the organic molecules provide flexibility and functionality ${ }^{[1]}$. Many polymer composite industries are trying to use inorganic filler in polymer matrix to improve the mechanical properties and to reduce the cost of the final product. Fly ash, an absolutely low cost inorganic waste product obtained from thermal power stations, is available abundantly and poses environmental hazards and disposal problems ${ }^{[2]}$. Fly ash mainly comprises alumino silicate, calcium oxide and Ferric oxide, which is used in construction industry because of its advantages such as low density, low cost, strong filling ability, smooth spherical surface, small and well distributed internal stress in the products and good processability of the filled materials ${ }^{[3]}$. But the usage in polymer industry is limited due to its weak interfacial's bonding between fly ash and polymer matrix and due to the low friction of the fly ash surface ${ }^{[4]}$. Surface treatment of fly ash with reactive silanes or surfactants, capable of graft formation is one of the principal methods for converting mineral of inorganic particulate filler into the materials bearing covalently bound functional groups and this treatment is used to enhance the mechanical properties of fly ash filled polymer composites. The surface area of fly ash filled polymer composite can be increased by reducing the particle size of fly ash and this enables uniform distribution in polymer matrix and improves the mechanical properties ${ }^{[5]}$. The surface treatment of fly ash with surfactant enhances the physical properties by avoiding particle-particle interaction and has a better distribution of fly ash within the polymer ${ }^{[6]}$. The use of silane coupling agent in polybutadiene rubber, improves the interaction between the rubber and fly ash and enhances the mechanical properties of the rubber ${ }^{[5]}$. Surface treatment of fly ash with acetone and silane improves impact properties than untreated fly ash in epoxy matrix ${ }^{[7]}$. Epoxy resin a thermosetting polymer has many advantages such as high strength and stiffness, good chemical and electrical resistances and low $\operatorname{cost}^{[8]}$. The use of unmodified epoxy resins based on bisphenol A-epichlorohydrin exhibits brittleness and low elongation after cure. To provide toughness enhancement, phase separation followed by the slow development of a two-phase morphology is critically important. Therefore, the modification of epoxy should be done to improve its toughening properties and also to get better the dispersion and interfacial bonding of fly ash in epoxy matrix ${ }^{[9]}$.

In this research work modification of fly ash was done using i) surfactant sodium lauryl sulfate and ii) silane coupling agent glycidoxy propyl trimethoxy silane and by iii) size reduction of fly ash was done upto submicron level using high pressure pulverizer. The surface treated fly ash was dispersed in amine containing liquid silicone rubber modified epoxy matrix. The effect of surface treatment of fly ash with varying filler loadings from 10 to $40 \%$ weight on the mechanical, morphological and thermal properties of modified epoxy was investigated.

\section{Materials and Methods}

\subsection{Materials}

Fly ash, Class F grade was procured from North Chennai Thermal Power Corporation (NCTPC) Chennai. Epoxy resin based on diglycidyl ethers of Bisphenol A (LY556) and hardener aliphatic amine triethyltetramine 
(HY951) from Huntsman, surfactant sodium lauryl sulfate (SLS) from Merck, silane coupling agent Glycidoxypropyl trimethoxysilane (GPTS) from Sigma Aldrich and other chemicals were procured from the local source. Amine containing liquid silicone rubber (ACS) a poly [dimethyl siloxane-co-(3-amino propyl) diethyl siloxane] having its grade AN102 was supplied by Resil Chemicals Ltd, Bangalore.

\subsection{Modification of epoxy resin}

The amine containing liquid silicone rubber modified epoxy was prepared by mixing the epoxy resin with 3 grams of amine containing liquid silicone rubber and heated at $50{ }^{\circ} \mathrm{C}$ for $30 \mathrm{~min}$ with constant stirring to have the same concentration in all the parts. Then the mixture was allowed to cool at room temperature ${ }^{[9]}$.

\subsection{Surface treatment of fly ash}

i) The silane coupling agent Glycidoxypropyl trimethoxysilane (GPTS) (2 gram) was mixed with $100 \mathrm{ml}$ of ethyl alcohol and 40 grams of fly ash was added. The mixture was stirred for the uniform distribution of the coupling agent to the filler. The mixing was done for about $45 \mathrm{~min}$ and it was filtered with the filter paper. The filtrate was then dried at $100{ }^{\circ} \mathrm{C}$ in a hot air oven for about $8 \mathrm{hrs}^{[5]}$. The silane treated fly ash was designated as SIL.

ii) Chemical modification of fly ash was done by taking 20 gram of fly ash mixed with $200 \mathrm{ml}$ of distilled water. The surfactant sodium lauryl sulfate was added in the concentration of $2 \% \mathrm{wt}$ and stirred for $6 \mathrm{hrs}$ at temperature of $60^{\circ} \mathrm{C}$ and then the samples were filtered and washed with distill water and dried in an oven for $48 \mathrm{hrs}$ at $60^{\circ} \mathrm{C}^{[10]}$. The sodium lauryl sulphate treated fly ash was designated as SLS.

iii) The particle size of fly ash was reduced by using a high pressure pulveriser by maintaining 7 bar pressure and its particle size distribution was analysed. The size reduced fly ash was designated as SUM.

\subsection{Preparation of composites}

The modified epoxy resin was mixed with unmodified fly ash in micron size (MIC), size modified fly ash in submicron level (SUM), sodium lauryl sulfate treated fly ash (SLS) and silane treated fly ash (SIL) at various loading (10, 20, 30 and $40 \%$ weight) were physically blended by stirring for 5-10 min. Then the hardener was added in the ratio of resin: hardener $(10: 1)$ and it was stirred for $10 \mathrm{~min}$. to prepare a homogeneous blend. The mould set up was kept in room temperature for $24 \mathrm{hrs}$ and then placed in a hot air oven heated at $100{ }^{\circ} \mathrm{C}$ for $3 \mathrm{hrs}$. The composition of epoxy with fly ash was shown in Table 1 .

\subsection{Characterization and testing}

The particle size distribution of the fly ash was measured by optical microscope using Biowizard Zoomaster IV optical microscope. The particle size distribution of pulverized fly ash particles was done using instrument Malvern Zetasizer Nano-series utilizing water as the dispersion medium. Fourier transform-infrared spectra of fly ash were recorded on ABB
MB 3000 FT-IR spectrometer by making the samples as disc using potassium bromide. The morphology of fly ash and its composites were examined by means of scanning electron microscope (SEM-JEOL JSM 850) and the magnification was varied from 100 to $10000 X$. Energy dispersive spectroscopy (EDX) of fly ash was analyzed for the elemental analysis. Thermo gravimetric analyses were done using TG AnalyzerModel Q50, TA Instruments, from 30 to $600{ }^{\circ} \mathrm{C}$ under $\mathrm{N}_{2}$ atmosphere with a flow rate of $40-60 \mathrm{ml} / \mathrm{min}$ with heating rate of $20^{\circ} \mathrm{C} / \mathrm{min}$. Mechanical properties such as flexural properties were carried out using UTM Shimadzu as per the ASTM D 790 standards at a test speed rate of $1 \mathrm{~mm} / \mathrm{min}$. Izod impact test was conducted on unnotched sample of size $60 \times 11 \times 3 \mathrm{~mm}$ as per ASTM D-256 standard to evaluate the toughness of the composite. An impact load was applied through a 2-4 J machine pendulum and the amount of energy absorbed before fracturing the samples was determined.

\section{Results and Discussion}

For good reinforcement the particle size should be finer and should have higher surface area.Using optical microscope, the particle size distribution of very fine particles of fly ash were determined. Here, required magnification of the particles is done, followed by selecting individual particles to determine their size. Then, in order to arrive at the average particle size a frequency table is drawn as shown in Table 2 and it was observed that $90 \%$ of particles were in the size ranging between $25-227 \mu \mathrm{m}$.

The particle size distribution of pulverised fly ash is shown in Figure 1. The data was used to find out the mean particle size, which was found to be between 500-600 nm (ie) in sub micron size and was designated as SUM.

The chemical composition of fly ash was determined by Energy dispersive X-ray microscope (EDX), which works on the principle that each element in the composition of fly ash emits peaks of varied frequencies. The chemical composition of fly ash used was given in Table 3. It reveals the abundant presence of silica as the main constituent along with alumina and traces of other oxides.

The morphology of fly ash and surface treated fly ash was analyzed using scanning electron microscopy. Figure 2a shows the SEM images of fly ash particles which are in

Table 1. Composition of epoxy and Fly ash composites.

\begin{tabular}{cccc}
\hline Composition & $\begin{array}{c}\text { Epoxy resin } \\
(\mathbf{g})\end{array}$ & $\begin{array}{c}\text { Fly ash } \\
(\mathbf{g})\end{array}$ & $\begin{array}{c}\text { ACS } \\
(\mathbf{g})\end{array}$ \\
\hline 1 & 100 & - & 3 \\
2 & 90 & 10 & 3 \\
3 & 80 & 20 & 3 \\
4 & 70 & 30 & 3 \\
5 & 60 & 40 & 3 \\
\hline
\end{tabular}

Table 2. Particle Size Distribution of Fly ash by Optical Microscope.

\begin{tabular}{ccc}
\hline codes & Range (micron) & \% \\
\hline 1 & $25-227$ & 90.75 \\
2 & $227-420$ & 8.9 \\
3 & $428-630$ & 1.02 \\
\hline
\end{tabular}


spherical shape with agglomeration and irregularly shaped amorphous particles can be detected and it is due to sudden cooling from high temperature ${ }^{[1]}$

The SEM image of silane treated fly ash is shown in Figure $2 \mathrm{~b}$. It is observed that the fly ash particles have interaction with silane coupling agent and the particles are well distributed and has less agglomeration formation. Figure 2c shows the SEM images of sodium lauryl sulfate treated fly ash. It is observed that the sodium lauryl sulfate was well coated on the fly ash particle which was expected to have good interaction with polymer matrix and also less formation of agglomeration.

Figure $3 \mathrm{a}$, b shows the SEM images of plain epoxy and modified epoxy. It is observed that the fracture surface of plain epoxy shows a thin line indicating a brittle fracture. On addition of amine containing liquid silicone rubber, the

Table 3. Chemical composition of Fly Ash (Class F).

\begin{tabular}{cc}
\hline Compound & Concentration (\%) \\
\hline $\mathrm{SiO}_{2}$ & 40 \\
$\mathrm{Al}_{2} \mathrm{O}_{3}$ & 19 \\
$\mathrm{Fe}_{2} \mathrm{O}_{3}$ & 6 \\
$\mathrm{CaO}$ & 2 \\
$\mathrm{MgO}$ & 3 \\
\hline
\end{tabular}

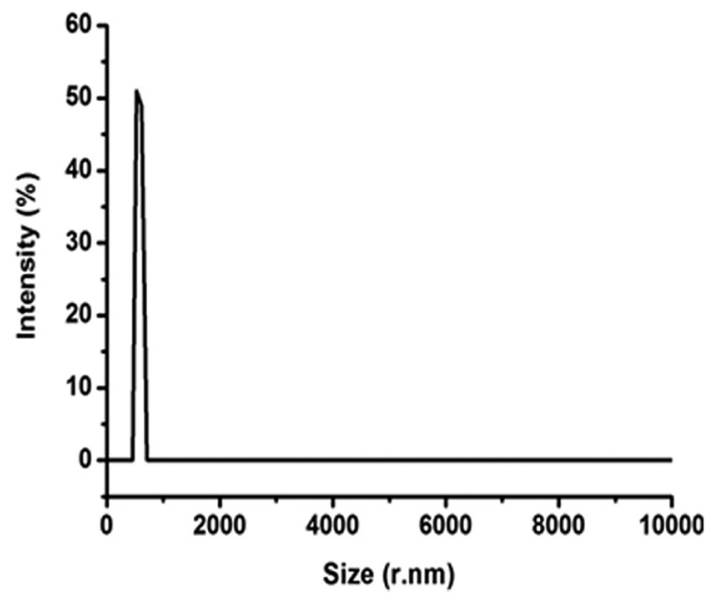

Figure 1. Particle size distribution of pulverised fly ash. rubber particles initially dissolve and become dispersed at a molecular level in the epoxy and get precipitated when epoxy cross linking takes place. This gives the required two phase morphology with the formation of rubbery particles dispersed and bonded to the cross-linked epoxy matrix.

The Figure 3c, d give the SEM images of fractured surfaces of epoxy fly ash (10\% MIC) loaded with and without modification of epoxy, and from these images it can be observed that there is a more uniform dispersion of the fly ash in the modified epoxy composites than in the unmodified epoxy, though the particles seem smaller in the unmodified epoxy composite. It can be assumed that the modification of epoxy by silicone can lead to better dispersion and distribution of the fly ash particle. This has been discussed in a few publications (eg) Altaweel et al. ${ }^{[12]}$ and Takahashi et al. ${ }^{[13]}$. Takahashi et al. observed that in silica filled epoxy composites, the filler distribution is better if the epoxy is modified by amine terminated silicone and this leads to an increase in flexural strength. It is to be noted that silicone is a rubbery polymer and a rubbery additive is expected to decrease flexural strength, but the flexural strength gets increased due to better polymer-filler interactions caused by the silicone modification of the epoxy. Altaweel et al. ${ }^{[12]}$, while studying the effect of ACS on epoxy-fly ash composites, gives evidence for the above, through free volume measurements.

The silane modified fly ash with modified epoxy composites seems to have a better dispersion of the fly ash as well as a lesser tendency to agglomerate, as shown in Figure $3 \mathrm{e}$ and the SLS modified fly ash with modified epoxy composites is shown in Figure 3f. Agglomeration tendency for fly ash particles seems to be present in SLS modified filler composite too (Figure 3e). The finest distribution of fly ash seems to be in the silane modified fly ash in modified epoxy in Figure $3 \mathrm{f}$

The FTIR spectra of unmodified fly ash is shown in Figure $4 \mathrm{a}$. The peak at $3500-3000 \mathrm{~cm}^{-1}$ is assigned to O-H bonding, the Si-O-Si bond assymmetric stretching is observed at $1600 \mathrm{~cm}^{-1}$. The FTIR spectra of silane treated fly ash is shown in Figure $4 \mathrm{~b}$. The peaks at $3500-3000 \mathrm{~cm}^{-1}$ is assigned to $\mathrm{O}-\mathrm{H}$ bonding and it is weak compared to pure fly ash due to the reaction between silane and fly ash particles. The $\mathrm{O}-\mathrm{H}$ group in $\mathrm{Si}$ coupling agent condenses with $\mathrm{O}-\mathrm{H}$ group of fly

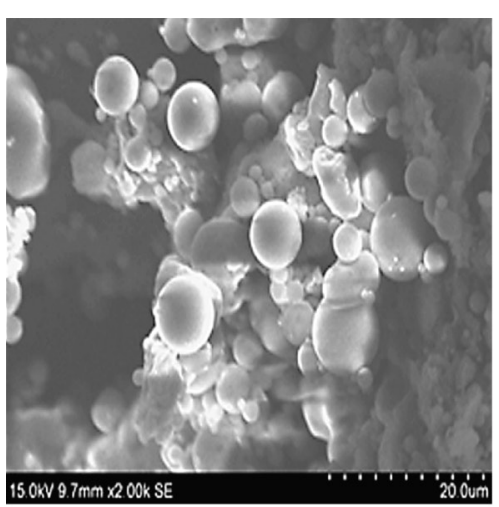

(a)

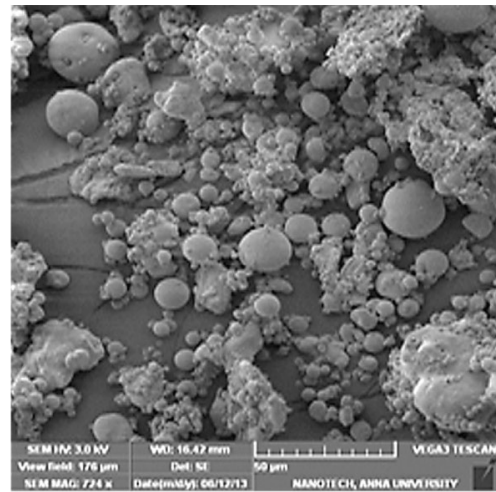

(b)

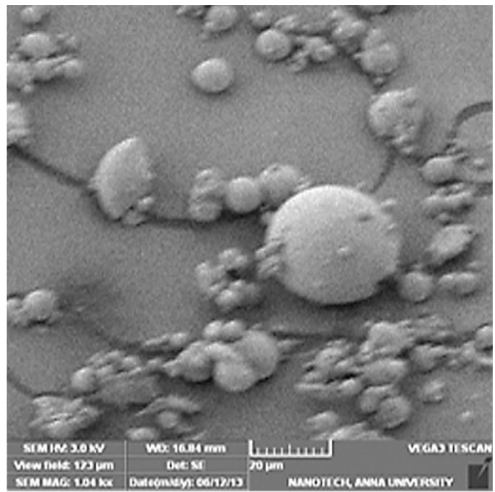

(c)

Figure 2. (a) SEM of fly ash; (b) SEM of silane treated fly ash; (c) sodium lauryl sulphate treated fly ash. 


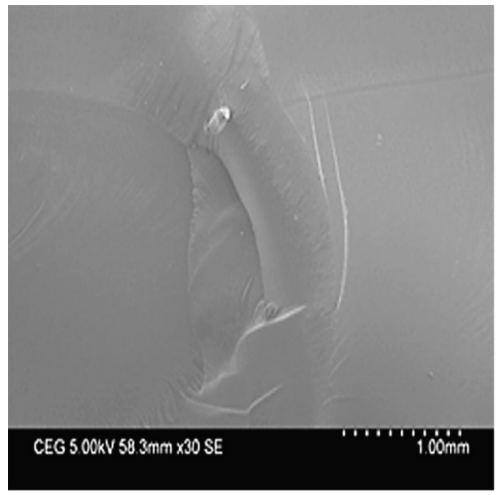

(a)

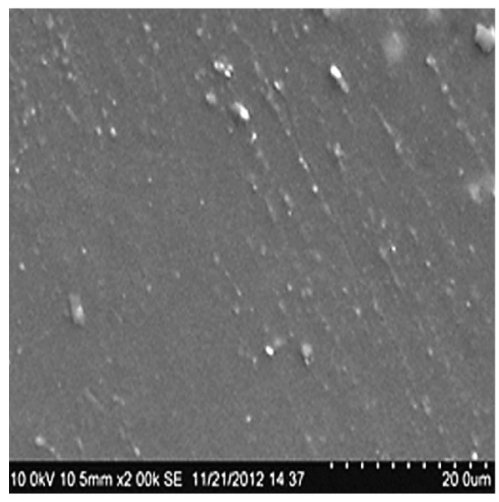

(d)

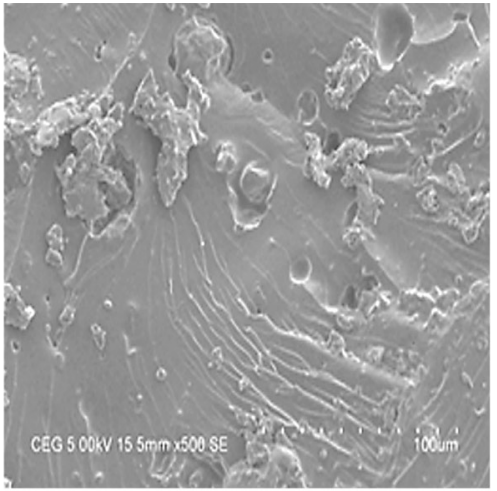

(b)

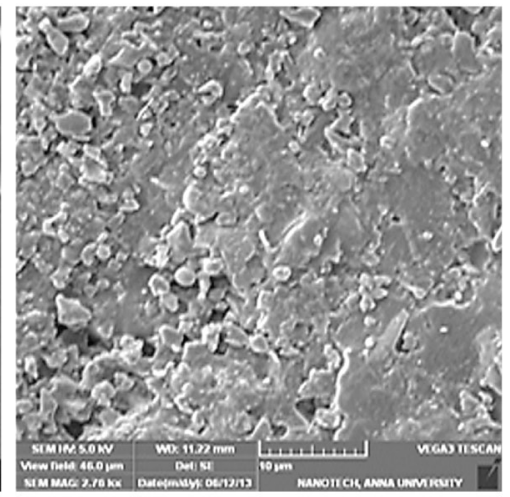

(e)

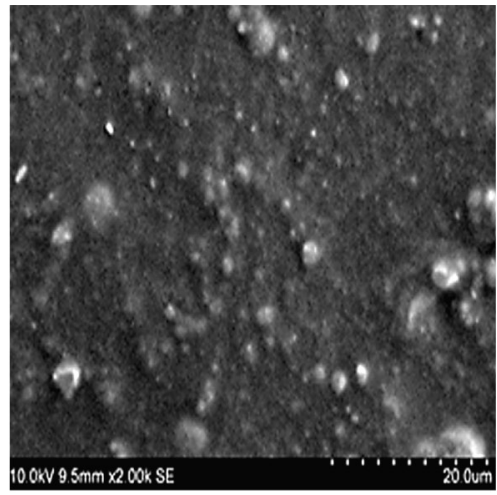

(c)

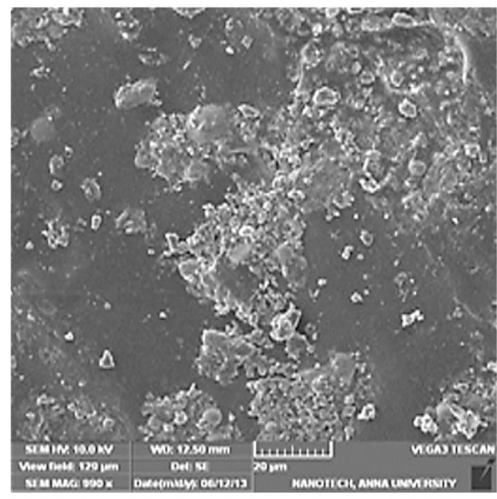

(f)

Figure 3. (a) SEM of unmodified epoxy; (b) SEM of modified epoxy; (c) SEM of epoxy fly ash (10\%) micron without ACS modification; (d) SEM of epoxy fly ash (10\%) micron with ACS modification; (e) SEM of silane modified fly ash with modified epoxy composites; (f) SEM of SLS modified fly ash with modified epoxy composites.

ash in an aqueous environment leading to the formation of covalent bond linkage for improving the resin wettability. The peaks at $2800 \mathrm{~cm}^{-1}$ are assigned to the $\mathrm{C}-\mathrm{H}$ stretch in the propyl chain and the peak at $1030 \mathrm{~cm}^{-1}$ is interpreted to the Si-O-Si bonds ${ }^{[14]}$.The FTIR spectra of sodium lauryl sulphate treated fly ash particles are shown in Figure 4c. It is observed that the peaks at the range of $1000-700 \mathrm{~cm}^{-1}$ are assigned for the vibration of Si-O and Al-O bonds. There is a slight shifting of band in the range of $1000 \mathrm{~cm}^{-1}$ to the higher wavelength because of the interaction of polar active SLS with the Si-O and Al-O bonds in fly ash ${ }^{[6]}$.

The FTIR spectra of plain epoxy is shown in Figure 5b. The peak observed at $3050 \mathrm{~cm}^{-1}$ is assigned to $\mathrm{C}-\mathrm{H}$ stretching of the oxirane ring, the $\mathrm{C}-\mathrm{H}$ stretching of aromatic and aliphatic group of methyl groups is observed at the range of $2960-2800 \mathrm{~cm}^{-1}$, the peak at $1600 \mathrm{~cm}^{-1}$ is assigned to stretching of $\mathrm{C}=\mathrm{C}$ of aromatic ring, the stretching of $\mathrm{C}-\mathrm{C}$ of aromatic ring is observed at $1509 \mathrm{~cm}^{-1}$, the peak at $1036 \mathrm{~cm}^{-1}$ is assigned to the stretching of C-O-C group of ether and the stretching of $\mathrm{C}-\mathrm{O}$ group of oxirane ring was observed at $900 \mathrm{~cm}^{-1[15]}$. The FTIR spectra of the amine containing liquid silicone rubber as modifier for epoxy is shown in Figure 5c. The stretching vibration of Si-O bond of $\mathrm{Si}-\mathrm{OH}$ is observed at $768 \mathrm{~cm}^{-1}$ and the stretching vibration of $\mathrm{Si}-\mathrm{CH}_{3}$ is observed around $1200 \mathrm{~cm}^{-1}$. The stretching vibration of Si-O is observed at $1010 \mathrm{~cm}^{-1}$ and the peak at

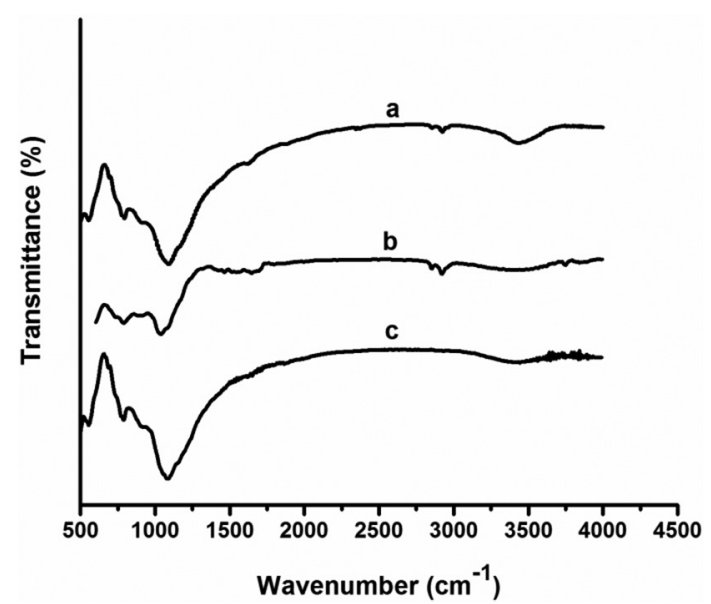

Figure 4. FTIR of (a) Fly ash; (b) Silane modified Fly ash; (c) SLS modified Fly ash.

$2950 \mathrm{~cm}^{-1}$ is assingned to the stretching vibration of C-H group $^{[16]}$. The FTIR spectra of amine containing liquid silicone rubber modified epoxy (ACS 3phr) is shown in Figure 5a. It is observed that a low intense peak is found in the range of $3500 \mathrm{~cm}^{-1}$, because 1:8 part of amine group is present in the modifier and this amine group reacts with the 


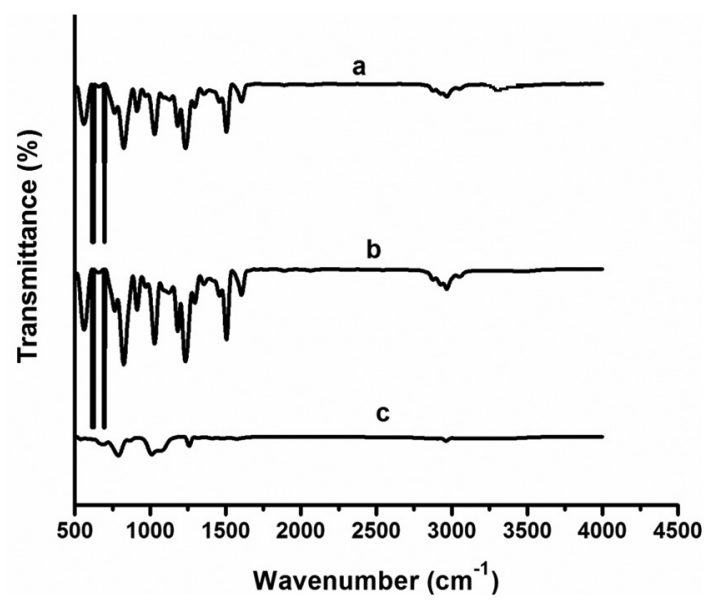

Figure 5. FTIR of (a) ACS modified epoxy; (b) pure epoxy; (c) Amine containing Silicone modifier.

epoxide group and some $\mathrm{O}-\mathrm{H}$ groups are formed. Then the modification at the peak of $900 \mathrm{~cm}^{-1}$ is due to C-O group of the oxirane ring opened by amine group.

The structure of amine containing liquid silicone rubber is shown in Figure 6.

The flexural strength of untreated and surface treated fly ash filled with modified epoxy composites is shown in Figure 7. It is observed that on increasing the fly ash loading from 10 to $40 \%$ weight, the flexural strength is found to be decreasing. Silane treated fly ash composites show an improvement in flexural strength compared to SLS treated fly ash and size reduced fly ash (500 to $600 \mathrm{~nm}$ ) modified epoxy composites. Altweel et al. ${ }^{[12]}$ too reported that fly ash content beyond $10 \%$ reduced flexural strengths in such composites.

Figure 8 shows the flexural modulus of untreated and surface treated fly ash filled with modified epoxy composites. The flexural modulus is found to be higher at $10 \%$ weight loading of fly ash for both untreated and treated fly ash. There is an increase in flexural modulus for $10 \%$ fly ash filler loading; comparatively treated fly ash has a higher flexural modulus than the untreated fly ash loading. The decrease in the flexural modulus of the composites after $10 \%$ filler is due to the poor interaction between the fly ash and epoxy matrix ${ }^{[10]}$. It may be due to the agglomeration of the fillers creating filler-filler interaction than polymer filler interaction.

The unnotched Izod impact strength of epoxy fly ash composites is shown in Figure 9. It is observed that the impact strength increases up to fly ash loading $30 \%$ weight and at $40 \%$ weight loading there is a decrease in the impact strength because of the high filler content, the polymer availability for filler interaction may be low ${ }^{[9]}$. Comparatively, surface modified fly ash composites show higher impact strength than the untreated fly ash because of the better dispersion.

The thermal stability and thermal degradation patterns of the composites are studied by thermo gravimetric analysis. The thermograms of modified epoxy and epoxy - fly ash composites are shown in Figure 10a, b. From the figure it is observed that the degradation for resins occurrs around<smiles>CCO[C@@](C)(CC)O[Si](C)(CCCN)O[Si](C)(C)CC</smiles>

Figure 6. Structure of Liquid Silicone Rubber.

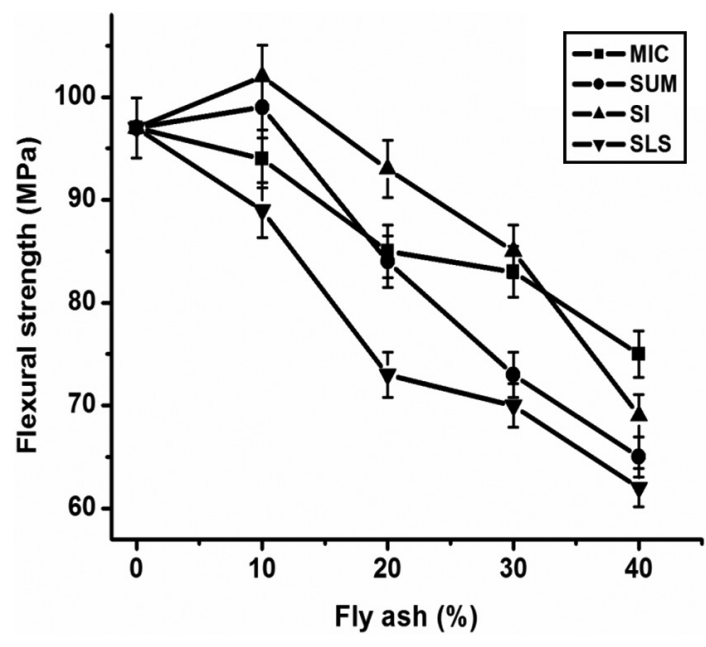

Figure 7. Flexural strength of surafce treated fly ash filled modified epoxy composites.

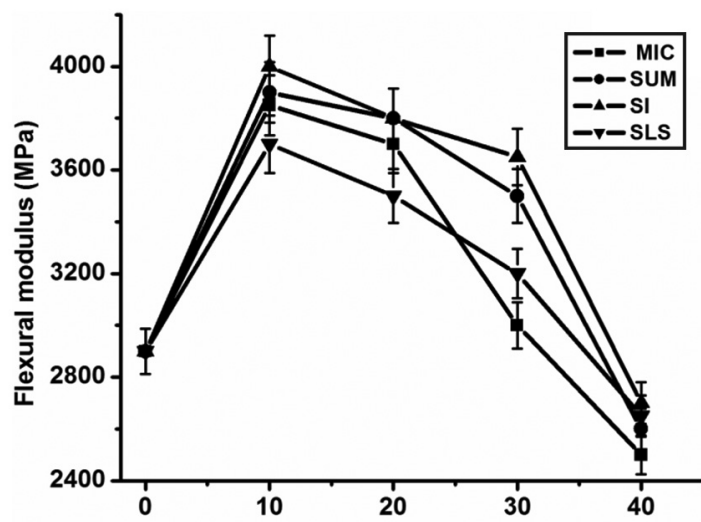

Fly ash (\%)

Figure 8. Flexural modulus of surafce treated fly ash filled modified epoxy composites.

$250{ }^{\circ} \mathrm{C}$, with $5-8 \%$ weight loss. This fact is attributed to the presence of impurities. The onset of degradation temperature starts at the temperature above $300{ }^{\circ} \mathrm{C}$ for almost all the composites. The char residue is high for $40 \%$ weight fly ash loading than $10 \%$ weight fly ash content. Epoxy has minimum char residue around $5 \%$ weight because of the presence of silicone in modified epoxy. It can be confirmed that the 


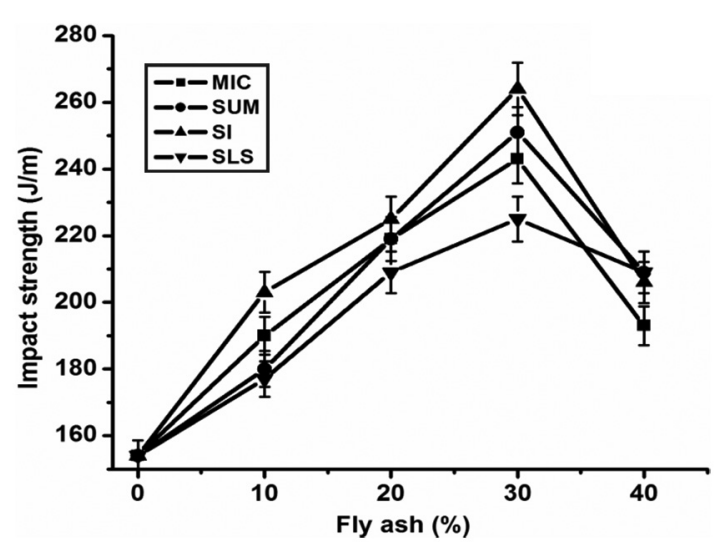

Figure 9. Impact strength of surafce treated fly ash filled modified epoxy composites.

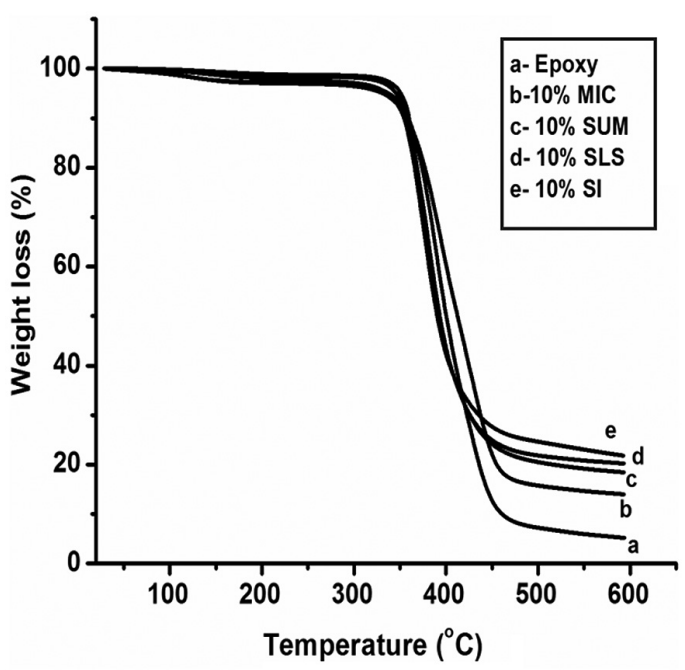

(a)

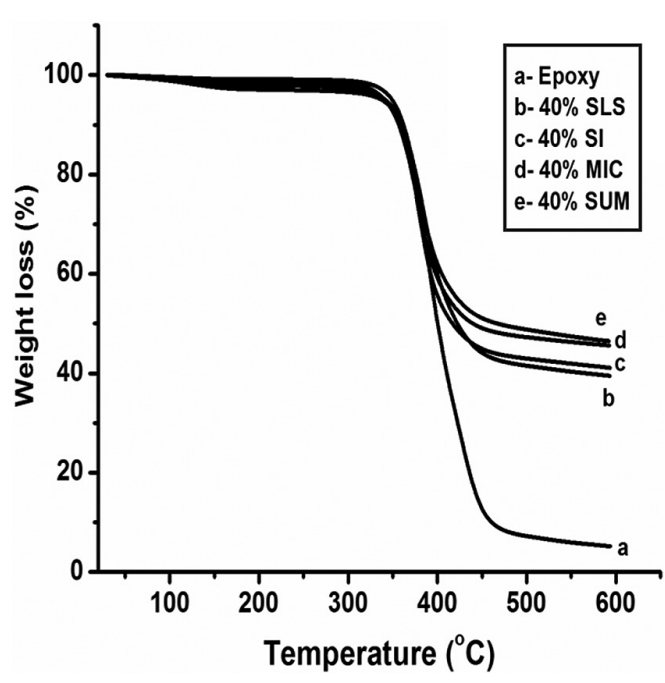

(b)

Figure 10. (a) TGA graph of ACS modified epoxy fly ash composites (10\%) loading; (b) TGA graph of ACS modified epoxy fly ash composites $(40 \%)$ loading stability of the blends is slightly increased with increasing fly ash content due to the high siliceous content of fly ash.

\section{Conclusions}

Modification of plain epoxy is done by adding amine containing liquid silicone rubber with the aim of reducing fly ash agglomeration formation and improving the dispersion of fly ash in modified epoxy matrix. Comparative studies were also made by surface treatment of fly ash using i) sodium lauryl sulphate, ii) GPTS and iii) size reduction by high pressure pulverizer.

SEM images show that silane coupling formation compared agent treated fly ash particles are well distributed and has less agglomeration to SLS treated fly ash. Silane treated fly ash composites show an improvement in flexural strength compared with SLS treated fly ash and size reduced fly ash filled epoxy composites (upto $10 \%$ fly ash loading). It is also observed that in SEM images of the composites and impact strength of fly ash composites increase upto $30 \%$ fly ash loading and on further loading it decreases. Silane treated fly ash composites show an increase in impact strength than MIC, SUM and SLS treated fly ash composites. The thermal stability of the epoxy fly ash composites is increased with the addition of fly ash. Based on the above observations, it may be stated that the addition of silane treated fly ash at $10 \%$ by weight of the resin, can be considered as a good composition for achieving good mechanical properties in modified epoxy composites.

\section{Acknowledgements}

The authors gratefully acknowledge Anna University for financial support to carry out this research work under Anna Centenary Research fellowship.

\section{References}

1. Akinci, A. (2009). Mechanical and morphological properties of basalt filled polymer matrix composites. Archives of Materials Science and Engineering, 35, 29-32.

2. Devi, M. S., Murugesan, V., Rengaraj, K., \& Anand, P. (1998). Utilisation of fly ash as filler for unsaturated polyester resin. Journal of Applied Polymer Science, 39(7), 1385-1391. http:// dx.doi.org/10.1002/(SICI)1097-4628(19980815)69:7<1385::AIDAPP13>3.0.CO;2-T.

3. Sreekanth, M. S., Joseph, S., Mhaske, S. T., \& Mahanwar, P. (2009). Effect of particle size and concentration of fly ash on properties of polyester thermoplastic elastomer composites. Journal of Minerals and Materials Characterization and Engineering, 8(3), 237-248.

4. Yang, Y. F., Gai, G. S., Cai, Z. F., \& Chen, Q. R. (2006). Purification and surface modification of fly ash. Journal of Hazardous Materials B, 133, 276-282.

5. Alkadesi, N. A. N., Hundiwale, D. G., \& Kapadi, U. R. (2004). Effect of coupling agent on the mechanical properties of fly ash-filled polybutadiene rubber. Journal of Applied Polymer Science, 91(2), 1324-1328. http://dx.doi.org/10.1002/app.13280.

6. Nath, D. C. D., Bandyopadhyay, S., Gupta, S., Yu, A., Blackburn, D., \& White, C. (2010). Surface-coated fly ash used as filler in biodegradable poly(vinyl alcohol) composite films: part 1-The modification process. Applied Surface Science, 256(9), 2759-2763. http://dx.doi.org/10.1016/j.apsusc.2009.11.024. 
7. Kulkarni, S. M., \& Kishore, (2002). Effects of surface treatments and size of fly ash particles on the compressive properties of epoxy based particulate composites. Journal of Materials Science, 37(20), 4321-4326. http://dx.doi.org/10.1023/A:1020648418233.

8. Singla, M., \& Chawla, V. (2010). Mechanical properties of epoxy resin - fly ash composite. Journal of Minerals \& Materials Characterization \& Engineering, 9(3), 199-210. http://dx.doi.org/10.4236/jmmce.2010.93017.

9. Mohammed Altaweel, A. M. A., Ranganathaiah, C., Kothandaraman, B., Raj, J. M., \& Chandrashekara, M. N. (2011). Characterization of ACS modified epoxy resin composites with fly ash and cenospheres as fillers, mechanical and microstructural properties. Polymer Composites, 32(1), 139-146. http://dx.doi.org/10.1002/pc.21030.

10. van der Merwe, E. M., Prisloo, L. C., Kuger, R. A., \& Mathebula, L. C. (2011). Characterization of coal fly ash modified by sodium lauryl sulfate. 2011 World of Coal Ash Conference (pp. 01-17). Denver: University of Kentucky. Retrieved in 10 May 2011, from http://www.flyash.info/2011/083-vanderMerwe-2011. pdf

11. Satheesh Rajaa, R., Manisekar, K., \& Manikandan, V. (2013). Effect of fly ash filler size on mechanical properties of polymer matrix composites. International Journal of Mining, Metallurgy \&. International Journal of Mining, Metallurgy \& Mechanical Engineering, 1(1), 34-37. Retrieved in 05 January 2013, from http://www.isaet.org/images/extraimages/IJMMME\%20 0101008.pdf

12. Altaweel, A. M. A. M., Ranganathaiah, C., \& Kothandaraman, B. (2009). Mechanical properties of modified epoxies as related to free volume parameters. The Journal of Adhesion, 85(4-5), 200-215. http://dx.doi.org/10.1080/00218460902881774.

13. Takahashi, T., Nakajima, N., \& Saito, N. (1989). Morphology and mechanical properties of rubber-modified epoxy systems. Amino-terminated polysiloxane. In C. K. Riew (Ed.), Rubber toughened plastics (Vol. 222, pp. 243-261). Washington: American Chemical Society.

14. Wu, G., Gu, J., \& Zhao, X. (2007). Preparation and dynamic mechanical properties of polyurethane-modified epoxy composites filled with functionalized fly ash particulates. Journal of Applied Polymer Science, 105(3), 1118-1126. http:// dx.doi.org/10.1002/app.26146.

15. González González, M., Cabanelas, J. C., \& Baselga, J. (2012). Applications of FTIR on epoxy resins - identification, monitoring the curing process, phase separation and water uptake. In T. Theophile (Ed.), Infrared spectroscopy-materials science engineering and technology (pp. 261-284). Rijeka: InTech Publication.

16. Launer, P. J. (1987). Infrared analysis of organosilicon compounds: spectra-structure correlations. In B. Arkles (Ed.), Silicon compounds: silanes \& silicones (pp. 100-103). Morrisville: Gelest.

Received: Mar. 19, 2015

Accepted: July 01, 2015 